Dialectologia 26 (2021), 187-211.

ISSN: 2013-2247

Received 6 May 2019.

Accepted 19 October 2019.

\title{
GENDER DIFFERENCES IN THE CONSTRUCTION OF ENGLISH NOUN PHRASES OF SDA COLLEGE OF EDUCATION STUDENTS
}

\author{
Abraham Kwadwo OKRAH, ${ }^{1}$ Veronica Serwaa Ofosu, ${ }^{2}$ Cecilia Ofosua OdAmE ${ }^{2}$ \& Joyce Senya \\ Ama ANKU \\ University of Ghana ${ }^{1} *$ / Asokore-Koforidua Ghana ${ }^{2}$ * \\ aokrah@ug.edu.gh / vsofosu@yahoo.com / ceciliaodame@yahoo.com
}

\section{Abstract}

The study is aimed at examining gender variation in the construction of noun phrases in an English essay quiz written by SDA College of Education students. The research design adopted was the quantitative content analysis with specific reference to descriptive design. Data were derived from 300 quiz scripts of SDA College of Education students who did English language studies in the $2015 / 2016$ academic year $\left(1^{\text {st }}-3^{\text {rd }}\right.$ year). Chi-square analysis was used to find out whether or not there were gender differences in the use of noun phrases in sentence construction and whether they were more or less significant and meaningful. The findings revealed that the female students used more complex noun phrases but they had single modifiers. The male students on the other hand used fewer complex noun phrases but with multiple modifiers.

\section{Keywords}

phrase, gender, content, College, SDA

\footnotetext{
* Department of Teacher Education, School of Education and Leadership P. O. Box LG 1181, University of Ghana, Legon, Ghana, West Africa.

* Department of Languages, S.D.A. College of Education, P. O. Box ASK 18, Asokore-Koforidua Ghana, West Africa.
} 


\section{DIFERENCIAS DE GÉNERO EN LA CONSTRUCCIÓN DE SINTAGMAS NOMINALES EN INGLÉS DE ESTUDIANTES DEL SEVENTH DAY ADVENTIST COLLEGE OF EDUCATION (SDA)}

\section{Resumen}

Este estudio tiene como objetivo examinar la variación de género en la construcción de sintagmas nominales a través de un cuestionario en inglés escrito por estudiantes del SDA College of Education. EI diseño de investigación adoptado fue el análisis de contenido cuantitativo con referencia específica al diseño descriptivo. Los datos se obtuvieron de 300 exámenes de estudiantes del SDA College of Education que realizaron estudios del inglés en el año académico 2015/2016 (1er-3er año). Se utilizó el análisis de chicuadrado para averiguar si existían o no diferencias de género en el uso de sintagmas nominales en la construcción de oraciones y si eran más o menos significativas. Los hallazgos revelaron que las estudiantes usaban sintagmas nominales más complejos, pero tenían modificadores únicos. Los estudiantes varones, por otro lado, usaron menos sintagmas nominales complejos, pero con múltiples modificadores

\section{Palabras clave}

frase, género, contenido, universidad, SDA

\section{Introduction}

Over the years, registers in English have extensively undergone stylistic change. This is probably in response to change in the perception of the reading public, one's purpose of communication, attitudinal choice of writers and gender differences. For example, Biber \& Finegan (2009) recorded how written prose registers in the seventeenth century differ from conversational registers, and how even by the eighteenth century, those registers evolved to become distinguishable from speech.

The idea of whether men speak differently from women has been discussed for centuries. This leads to the idea of gender. Gender has been used in Anglo-Saxon discourse to stand for the social, cultural and psychological meaning imposed upon biological sexual identity (Shields \& Dicicco 2011). Amott \& Matthaeil (1991) explain that gender is not natural or biological category which is unchanging over time and across culture; rather, it is socially constructed. The idea of gender helps one to differentiate the biologically founded sexual differences between men and women from the way culture determines differences between the roles assigned to men and women respectively in a particular society. In the 1960s, feminist movements saw that one of the ways men 
dominated society was through language. That is, men's language was seen as the standard form and that of the woman as a sub-standard of men's language. Many of the researchers in this field researched into men's language. For example, Labov (1972) researched into the speech of men. Much later, other writers became interested and started looking into observable difference in language use by males and females. Writers like Coates \& Cameron (1989) assert that how much one speaks is influenced by the speaker's audience and the subject matter. They further say that if a large collection of different studies on language and gender are put together, it would be realized that there is marginal difference between how much men and women speak. In contrast, Brizendine (2006), in a more recent research, states that men talk less three times as women. Drass (1986) on the other hand, found that men speak more than women in an experiment conducted on gender identity in conversation dyads.

Many works on gender have argued that there are variations in the way the different genders use language (Peterson 2000; Soori \& Zamani 2012). Many scholars have also attempted to find out whether there are gender differences in spoken and written discourses (Grob, Meyers \& Schuch 1997; Philips \& Reynolds 1987). Studies into differences in language use by males and females are on the increase. Some studies suggest that no differences exist in male and female language and even if there were, they are insignificant (Crawford 1995). Other writers believe that there is evidence of differences in language use by males and females. Maccoby et Nagy (1974), Philips \& Reynolds (1987) and Coulmas (2006) are of the view that certain linguistic forms and different kinds of speech behaviour distinguish men as men and women as women.

There have been two general conclusions which dominate the literature on women's language. Many writers such as Lakoff (1975) and Kramer (1974), for example, assert that there is a women's language. Writers like Key (1975) and Butler (1990) believe that women show preference for certain linguistic forms whereas O'Barr \& Atkins (1980) conclude that the evidence is insufficient. In 1975, Lakoff made a research publication on women's language and identified several features of a women's speech. The features fall into four broad categories namely: lexical items, syntax, intonation and hyper-politeness. According to her, in terms of lexical items, women use more "hedge words" such as "I 
think", "kind of" and "sort of" and each of these lexical items represents the relegation of women (in both their conversational topics and their linguistic forms) to the trivial and inoffensive. In contrast, Thorne, Kramarae \& Henley (eds.) (1983) are of the view that both sex of speaker and sex of listener may not be considered important to the frequency of use of tag-questions, qualifiers or hedges. Haas (1979) also presents some proof that girls use more adjectives than boys. Kramer, in support of this claim, opines that women do not only use such words, but use them "in contexts and in frequencies that differ from men" (Kramer 1974: 15). Lakoff argues that women use more modals. According to her, that modals can be used to express hesitancy, so they are usually unwilling to take any major stance in the public domain (Lakoff 1975a).

Intonation is another aspect of language which is often cited as showing evidence of a woman's language. According to Lakoff (1975b) women use a certain kind of sentence intonation pattern which changes a declarative answer into a question. Frank (1978) suggests that physiology alone cannot account for all the differences in male and female pitch. Brend (1975), in her research, claims that intonation preferences vary between men and women. However, the nature of her study is not described, nor the statistical spread of her findings given. Frank (1978) is of the view that Brend's article is intriguing but it is far from definitive, as she gives no indication of the source of her data or of her methods of collection (Frank 1978). Thus, neither study supports Lakoff's assertion that a woman's intonation pattern exists. Lakoff supports her own argument that "women's language" features seem to function to place women in a subordinate social position. In as much as the importance of Lakoff's work cannot be disputed, both her methodology and conclusions are questionable by modern standards. Lakoff drew her data from introspection (into her own speech) and that of her friends. Furthermore, the use of Lakoff's own friends as informants must have altered the informant pool. It cannot be judged whether her conclusions would have changed, had she taken a more representative sample of the population. However, similar, but independent, studies conducted by other researchers are consistent with Lakoff's findings. Herring (1994, 2019), for instance argues that women display features of attenuation-hedging, apologising, asking questions rather than making assertions.

Most of the studies conducted on gender variations have focused on spoken language rather than written language. For instance, Chambers (1992), Labov (1972) and 
Trudgill (1974) researched into gender-variation of language use on the phonological and lexical levels. They agree that the gender of interlocutors plays an important role in phonetic and phonological variation and support the idea that males use phonetic variants that are different from those used by females for some of the phonemes in their respective dialects. In addition to phonological variations, some scholars have observed that there is syntactic variation between males and females' language. Rydén (1979), for instance, asserts that social factors are not much involved in syntactic variation between male and female's language. Others argue that syntactic variation is conditioned less by social factors and by language internal cognitive and situational constraints (Scherre \& Naro 1992). The English Noun Phrase (NP), especially, has been found to show gender variations (Biber 1997). The importance of the grammatical features of the complex English NP has been identified by many researchers such as Biber et al. (1999). The English Complex NP includes a noun and some sort of modifications.

Baron (2004) explains that there are not many studies conducted on gender differences in written discourse. Many of the studies done were on spoken language which draws upon direct observation, interviews or transcriptions appearing in large-scale corpora. Also, Biber (1988) opines that noun phrases with modifiers are relatively rare in oral discourse but they are notably common in written discourse so using spoken discourse needs to be complemented with written discourse. This informed the researcher's choice of the written discourse instead of the spoken one. According to Biber et al. (1999), an NP is defined as a head noun/obligatory, along with all of its modifiers that come before and after it. Crystal (2004) claims that in the English NP, the head noun acts as the centre or core upon which its constituents can be built. Biber asserted that an NP can be categorized as simple or complex, depending on how many constituents are present in the phrase. However, the determination as to what makes an NP simple or complex seems to be fluid and researcher dependent. Biber et al. (1999) determined a complex NP to contain more than four words. DeCapua (2017) explains how complex NP is because it contains more elements than just a determiner followed by an optional adjective and a noun. Quirk, Greenbaum, Leech \& Svartvik (1985) identify three components of complex noun phrases. These are the headword, the premodifiers and the 
postmodifiers. They further assert that premodifiers encompass all the items placed before the headword. They are mostly adjectives, participles, adverbs and nouns and they nestle themselves between the determiners and the head noun (Biber et al. 1999; Quirk et al. 1985), with their main function being, to categorize, classify, label, and describe the head noun. A postmodifier comprises all the items placed after the head. According to Biber et al. (1999), the Longman Grammar of Spoken and Written English (LGSWE) identifies two major types of structural postmodification. These are phrasal and clausal postmodifiers (Biber et al. 1999: 604-605). Under the phrasal postmodifiers, Biber et al. further identified the following: prepositional phrases (PP), adjective phrases (AdjP), adverb phrases (AdvP), noun phrases in apposition (NPinApp), and reflexive pronouns (Refl). Clausal postmodifiers can also be grouped under finite and non-finite (Biber et al. 1999: 604-605). Finite clausal postmodifiers are relative clauses (RC). Non-finite clausal postmodifiers are -ed clauses, -ing clauses, and to-clauses.

The study was limited to selected English essay quiz scripts of the students. This is because the incorporation of tutors' alterations is limited compared to project works and long essays. The focus was on only what the students wrote. Tutors' alterations, if any, will not be considered as part of the writing. One essay type question which was answered by all the students was selected. In Ghana, College of Education students have to learn English and rules of the English language in order to communicate verbally or in writing. One of these rules is the grammatical features, especially Noun Phrases. Philips \& Reynolds (1987) claim that the language of women is more complex than that of men. The question is, if complexity is a feminine feature, will it reflect in the noun phrase construction of female students of SDA College of Education? Will the English noun phrase construction by SDA College of Education students authenticate the view that social factors are not much involved in syntactic variation or prove otherwise? The pursuit for answers to these questions forms the basis of the study. The fundamental objective of this study is, therefore, to explore gender variation in the use of noun phrases (NP) in English. 


\section{Methods}

\subsection{Research design}

The research design used in this study was both quantitative and descriptive design. It did not, however, involve either a questionnaire or an interview but purely quantitative content analysis of students' English quiz essay scripts. As done in a descriptive design, a sample was drawn from the population of interest, which is, the students of SDA College of Education's scripts. The responses which were NP contractions in the students' essay were studied and generalizations after the study were made. The use or choice of descriptive design made the study practical because physical data was available for study. In this study, descriptive design was the best to choose where the population involved in the study was large. The data collected through descriptive design represents field condition. The study aimed to focus on counting and classifying features and construct tables and figures to explain the observed data. The quantitative approach helped to bring about a clear picture of what to expect in the research. According to Best and Khan, cited in Amedahe (2002), descriptive research concerns itself with conditions or relations that exist, such as, practices, attitudes and opinions that are held. Amedahe (2002) also argues that in descriptive research, there is accurate description of activities and this goes beyond mere fact-finding. He gives some of the characteristics of descriptive research as randomization so that errors may be estimated when population characteristics are inferred from observation and samples; and presentation of data chronologically in order to arrive at valid and accurate conclusions.

\subsection{Sources of data}

The data on which the study is based was derived from quiz scripts of SDA College of Education students who did English language studies in 2015/2016 academic year (1 ${ }^{\text {st }}$ $3^{\text {rd }}$ year). A quiz essay which is a form of test was used. This was chosen because it is one of the most recognized and frequently used methods in assessing students at the training 
college. Also, the use of quiz scripts precluded the intervention of the researchers in the production of the data. This made the data more "original" than one which is obtained through a questionnaire or an interview, because the students did not have the least idea that their scripts would be used for research purposes at the time of writing. Thus, no "intentionally created" research environment was set up for the purpose of collecting the data. The quiz scripts collected was in the written mode. One main challenge associated with using written language in research is the incorporation of teacher's alteration on the marked scripts. However, this is minimal in quiz scripts because teachers' alterations normally come in during marking (that is, when the student has finished his or her part) or do not come in at all. So, during analysis, the teacher's alteration, if any, was not included.

The choice of English language studies was influenced by the fact that it is a course that is offered by all the students in first, second and third years, thus justifying the generalization of the findings of the study. Also, being a general course for all the levels, it was believed that the students' style of writing had been influenced as compared to the second cycle. Information provided by the vice principal (academic), gave the number of students who offered English language in 2015/2016 academic year as 1400. Out of this number, 520 were in level 100, 450 were in level 200 and 430 were in level 300.

\subsection{Sample and sampling technique}

The target of interest was the scripts of SDA College of Education students. The sampling frame was selected scripts written by the students. With the total number of 1400 students, 300 scripts of students were used. A multi-stage sampling approach was used to select the 300 scripts. Sarantakos (1998) points out that a multi-stage sampling approach involves using more than one sampling technique to select one's respondents. Under this, the three main sampling methods - purposive (non probability), stratified and simple random were used. All the three sampling methods were employed at various stages of the study to get the required scripts.

It was observed that the students of the college were grouped into twelve. The groups were General 1 to General 9 and Early Childhood 1 to 3 (G1-G9 and E1-E3). A simple random method was used to select ten groups from which three hundred scripts 
were sampled. The reason for selecting ten groups was to make the sampling easy. Both stratified random and simple random sampling methods were employed at that stage to select the three hundred scripts. The stratified sampling was used to achieve gender balance. The three hundred scripts were made of a hundred and fifty from male students and a hundred and fifty from female students. Since the quiz scripts did not bear the names of the students but only their index numbers, the researchers requested for the class list which bore the names and index numbers of the students who were in the groups that were sampled. This was courteously granted. The students were informed that some of their essay quiz scripts would be used for research. They were assured that the selected scripts were solely for research and not for any other purpose. Again, they were told their names would not be identified. So, based on the students' names and index number in the class list and their index number on the script, the scripts were put in each group into that of males and females. This was done with an assistance of colleagues who were familiar with many local names. This notwithstanding, scripts that the gender could not be determined by just their names were not sampled.

Simple random sampling was used to select the scripts. The fishbowl draw, a method of random sampling, was used to sample thirty scripts (fifteen from each gender) from each of the ten sampled groups. To achieve this, the names of the students who wrote the test were grouped under males and females in alphabetical order. The names were numbered, and each number written on pieces of paper. The pieces containing the numbers of the male students were put into a box then picked out in turn without looking into the box until the number required were picked. The scripts of students whose numbers were picked were selected for the analysis. The same procedure was used to select the scripts for the females.

Photocopies of the selected scripts were made for the analysis and the original scripts returned to the office of the vice principal. The analysis was based on the first two hundred words of each script. This was to ensure equality in length of text. 


\subsection{Data analysis procedure}

The identification and analysis of the noun phrases was done manually because a computer parse was not available and because - to the best of our knowledge - as yet none exists that could have yielded all the details we were interested in. However, the researchers used personal computers $(P C)$ to sort, count and add all the noun phrases in the data. We began by reading through each script with the view of identifying noun phrases in them. Any noun phrase identified was circled with a red pen and written on a sheet of paper. Noun phrases within quoted expressions were excluded since they did not emanate from the students themselves. Though pronouns are considered simple noun phrases, they were excluded, because they do not lend themselves to any syntactic variation to be influenced by gender. Personal names were also excluded. In all a total of 17,880 noun phrases $-8,870$ from the female students and 9,010 from the male students - were extracted from the 300 scripts.

After identifying the noun phrases from the scripts, the researchers had them typed into a computer and manually sorted into the various details they were interested in. The researchers worked on the noun phrases from each script separately and later added that of all males together as well as that of females. Microsoft Office Excel was used to do all the quantitative analysis together with the drawing of tables. To conceal the identity of the students, the scripts labelled F1 to F150 and M1 to M150 on females' and males' scripts respectively. NPs used as examples from the same scripts were given the same numbers for easy identification.

The researchers analysed the NPs found in the quiz essay writings of SDA College of Education students using content analysis. Content analysis is a research tool which focuses on the actual content and internal features of a text. According to Palmquist (2013), it is used to determine the presence of certain words, concepts, themes, phrases, characters, or sentences within texts or sets of texts and to quantify their presence in an objective manner.

The researchers grouped the scripts into six. Each group was made of fifty scripts. The first three groups which totalled 150 were for the females and the last three groups made up of 150 scripts were for the males. The researchers then identified all NPs in the first three sects. They were numbered and copied on a separate sheet. The same 
procedure was used to identify the NPs in the last three sects which were for the males. The numbering of the males was done differently. The researchers then grouped both the females and males NPs identified according to the types they wanted. For example, simple NP, complex NP, concatenated NP, etc. After that they interpreted the data obtained from each group based on the types.

\subsection{Reliability and validity}

Reliability and validity are two issues that any researcher should be concerned about while designing a study, analysing results and judging the quality of the study (Patton 2001). They help the researcher to persuade his or her audiences that the research findings of an inquiry are worth paying attention to (Lincoln \& Guba 1985). Reliability refers to the extent to which results of research work are consistent over time, and an accurate representation of the total population under study (Joppe 2000 cited in Golafshani 2003). Validity, on the other hand, determines whether the research truly measures that which it was intended to measure or how truthful the research results are. To ensure that the data that was collected and analysed would be reliable and valid, the researchers employed three strategies in the course of analysing the data. First, random sampling procedure, specifically, the fishbowl draw, was used. This method was used to select thirty scripts each from the various group of study. This helped to bring about fairness in the selection of participants. The numbers that were picked from the box corresponded with the scripts of students the researchers used for the analysis. The procedure used for the selection of the females' scripts was the same for the selection of the males. The peer scrutiny was also used to achieve reliability and validity in this study. This is where the researchers sought the help of colleagues or people with knowledge in the area of study to examine the research under study and give their suggestions where necessary. This strategy was adopted at two different stages. The first was during sorting the examination scripts into males and females. Though the researchers were conversant with most of the local names, there were few names that they were not familiar with. Colleagues who were familiar with such names were asked to verify them. The other 
stage was during the data analyses. To ensure its reliability and validity, six of the scripts - three from each gender - were photocopied and given to a colleague who is an English tutor to analyse. The results, when compared, corroborated those of the researchers.

\section{Findings}

The purpose of the study was to examine gender variation in the construction of noun phrase in an English essay quiz written by SDA College of Education students. The following gives details of the research findings.

\begin{tabular}{lcc}
\hline RESPONDENTS & FREQUENCY & Percentage (\%) \\
\hline FEMALE & 2,850 & 46.0 \\
MALE & 3,350 & 54.0 \\
\hline TOTAL & 6,200 & 100.0 \\
\hline
\end{tabular}

Table 1. Production of simple NPs by both males and females.

As can be seen from Table 1, the total number of simple NPs produced by both female and male students was 6,200. Out of this number, the female students produced 2,850 which represents $46.0 \%$ while the male students produced 3,350 representing $54.0 \%$. The chi-square analysis shows that there was gender difference in the use of simple NP constructed by the students and that the difference was significant. (Observed for females $=2850$, observed for males $=3350$, expected $=3,100)$ chi-square $=2.15 E-10$, P-Value 0.000. This shows that the male students used simple NPs more than the females.

\begin{tabular}{lcc}
\hline RESPONDENTS & FREQUENCY & Percentage (\%) \\
\hline FEMALE & 6,020 & 51.5 \\
MALE & 5,660 & 48.5 \\
\hline TOTAL & 11,680 & 100.0
\end{tabular}

Table 2. Production of simple NPs by both males and females. 
In the case of complex NPs, a total of 11,680 (Table 2 ) structures were produced by both genders. Out of that, 6,020 representing $51.5 \%$, was used by the female students, while 5,660 representing $48.5 \%$ was used by the male students. The data shows that the female students used complex NPs in their writings more than the male students. The chisquare analysis gave the return as $0.000865(p$ value $=0.000)$. That the women used complex NPs more than the men is evidenced when one compares the complex NP produced by each gender with the total NPs produced by that same gender. The female students produced a total of 8870 NPs while the male students produced 9,010. From the above analysis, it can be said that $67.8 \%$ of the total NPs used by the female students was complex while $62.8 \%$ of the men's total NP was complex. Such regular use of the complex NP by the female students more than the males' supports Philips \& Reynolds' (1987) claim that women's speech is more complex than that of men's. It therefore shows that differences exist between female's and male's language. This gives recognition to the claim by researchers (Maltz \& Borker 1982; Sheldon 1990; Tannen 1990, 1994) who follow the culture/difference approach of gender and language theory that men and women speak differently.

Under the complex noun phrases, two types were evident in the data. There were complex NPs with Single Modifiers and those with Multiple Modifiers.

\subsection{Single and multiple modifiers}

Single Modifier is used in this study to describe complex NPs that have only one modifier, whether at the pre-modification or post-modification level. Examples of the single modifiers from the data are below.
1a. Entire students - F22
1b. Students there - F45 
In the above examples, entire and there are the only modifiers in NPs 1 and 2 respectively. In the first structure, entire is a single modifier at the pre-modification level while there is a single modifier at the post-modification level.

Multiple modifiers are those complex NPs which the internal constituents have more than one modifier modifying a single head whether at the pre-modification or postmodification level. Internal constituent means a word, phrase or clause forming part of a larger grammatical construction so in this case we look at the number of modifiers modifying a head noun in a structure. For example:

2a. Regulations on school discipline ${ }^{1}$ taken by the school authorities ${ }^{2}$

which did not favour the students ${ }^{3}-\mathrm{M} 30$

2b. A tall fair-skinned $^{2}$ Ewe $^{3}$ lady who was an SRC executive $e^{4}-\mathrm{F} 50$

In example 2a, there are three different modifiers that modify the head noun regulations. These are, on school discipline, taken by the school authorities and which do not favour students and in example 2b, the modifiers are: a tall, fair-skinned, Ewe and who was an SRC executive.

\begin{tabular}{lll}
\hline RESPONDENTS & FREQUENCY & Percentage (\%)
\end{tabular}

\begin{tabular}{lrr}
\hline FEMALE & 3,082 & 52.2 \\
MALE & 2,820 & 47.8 \\
\hline TOTAL & 5,902 & 100.0
\end{tabular}

Table 3. Production of single modifiers.

The figures in Table 3 show that out of the total of 5,902 single modifiers collected, the female students used 3,082 which represents $52.2 \%$ while the male students used 2,820 representing $47.8 \%$. (Chi square $=0.00064874, p$-value $=0.000$ ). The chi-square analysis shows that the female students used more single modifiers than the males and that the difference is significant. Examples of single modifiers are: 


$$
\begin{array}{ll}
\text { 3a. } & \text { Nice gentleman - M38 } \\
\text { 3b. } & \text { First speaker - F15 } \\
\text { 3c. } & \text { Fresh students - F50 }
\end{array}
$$

\begin{tabular}{lcc}
\hline RESPONDENTS & FREQUENCY & Percentage \% \\
\hline FEMALE & 2,528 & 49.0 \\
MALE & 2,630 & 51.0 \\
\hline TOTAL & 5,158 & 100.0 \\
\hline
\end{tabular}

Table 4. Production of multiple modifiers.

The total number of multiple modifiers produced was 5,158 (Table 4). Out of this number, the female students used 2,528 representing $49.0 \%$ while male students used 2,630 also representing $51.0 \%$. This shows that the men used more multiple modifiers in their writing than the women in terms of frequency use, but the Chi-square analysis shows that the difference in use of multiple NP is marginal. (Chi-square $=0.15554, p$ value $=0.16$ ). While differences existed in the use of single modifiers, there was no significant difference in the use of multiple modifiers. An example of phrases which had a high number of internal constituents is:

4. A yearly programme that is performed at all colleges by the various authorities to allow the freshers to be ushered and accepted into the college system - M28

In example 4, for instance, the headword, programme, is modified directly by $a$ yearly and that is performed. The other modifiers in the phrase are: at all colleges, by the various authorities, to allow the freshers to be ushered and accepted into the college system.

\subsection{Types of multiple modifiers}

Evident in the data also was the two types of noun phrases with multiple modifiers. These were phrases with embedded modifiers and those with concatenated modifiers. 


\subsection{Embedded modifiers}

The complexity of the NP was analysed to establish the level of embedding that occurred for each sample of the NP with embedded modifiers. Table 5 gives the number of NPs that occurred not as heads of arguments in a clause structure but as a modifier. If an NP modifies the head of a clause argument, it is considered to be embedded at level one. NPs modifying a level one embedded NP are at level two; NPs modifying a level two embedded NP are at level three and so on. Level one embedded modifiers were discussed under single modifiers and to avoid duplication, they were not discussed here. NPs with embedded modifiers at levels two, three, and four are illustrated in examples $5 a, b$ and $c$ respectively.

5a. The privilege of attending a party ${ }^{1}$ organised by the school authorities ${ }^{2}-M 56$

b. The chance of giving information ${ }^{1}$ bothering on issues ${ }^{2}$ of discipline ${ }^{3}-\mathrm{M} 48$

c. A reward to teachers ${ }^{1}$ who taught students ${ }^{2}$ who passed in subjects ${ }^{3}$ that were difficult ${ }^{4}-$ M82.

In example 5 a above, the head noun privilege is modified only by - of attending a party. The other modifier in the phrase, organized by the school authorities, does not modify the head noun privilege but modifies the party in the preceding modifier. Thus, organized by the school authorities, is an embedded modifier at level two. With example $5 b$, the head noun chance is modified by - of giving information. The modifier bothering on issues modifies the information in the preceding modifier while of discipline modifies on issues. Of discipline is an embedded modifier at level three. Example $5 c$ has reward as head noun modified by to teachers and the modifier teachers is modified by who taught students and the modifier students in turn is modified by who passed in subjects and subjects is modified by that were difficult. That were difficult is an embedded modifier at level four. 
Level 2

\begin{tabular}{lccccccc} 
& Level 2 & \multicolumn{3}{c}{ Level 3 } & Level 4+ \\
\hline RESPONDENTS & FREQ & $\%$ & FREQ & $\%$ & FREQ & $\%$ & TOTAL \\
\hline FEMALE & 624 & 40.4 & 304 & 40.3 & 96 & $45.5=1024$ \\
MALE & 920 & 59.6 & 450 & 59.7 & 115 & $54.5=1485$ \\
\hline TOTAL & 1544 & & 754 & & 211 & $=2509$
\end{tabular}

Table 5. Embedded modifiers.

With embedding at all levels, a total of 2,509 modifiers were identified in the data. Female students used 1,024 (40.8\%) while the male students also used 1,485 (59.2\%). Once again, the Chi-square computation confirmed that difference in the use of embedded modifiers was significant. It yielded (Chi-square $=3.4664 \mathrm{E}-20, \mathrm{p}$ value $=0.000$ ) at all the levels. For level two embedding, the female students used 624 which represents $40.4 \%$ while the male students used 920 representing $59.6 \%$. In the case of embedding at level three, the female students produced 304 which represent $40.3 \%$ while the male students also produced 450 representing 59.7\%. At the level four embedding, 96 which represents $45.5 \%$ were produced by the female students, while 115 representing $54.5 \%$ were also produced by the male students. That the male students used embedded modifiers more than the female students confirms the existence of variation in the use of language by the two genders.

\subsection{Concatenated modifiers}

An NP is said to contain concatenated modifiers if it has two or more modifiers which modify the same head noun (Quirk et al. 1985). In example 2a repeated as example 6 , all the modifiers modify the same head noun regulations.

6. Regulations on school discipline ${ }^{1}$ taken by the school authorities ${ }^{2}$ which did not favour the students ${ }^{3}-\mathrm{M} 30$

The different modifiers which modify (the head noun) regulations are on school discipline, taken by the school authorities, and which did not favour the students 
Next, the complexity of the concatenated phrases was analysed to establish the number of modifiers used in each concatenated phrase. Examples 7a, b, and c illustrate NPs with concatenated modifiers at levels two, three, and four respectively.

7a. Message from the principal to the students - F34

7b. An interesting programme organised by the hall executives for the freshersF36

7c. Important duties in the school performed by some prefects on campus, which are very helpful in ensuring that the school environment gets friendly-M64

In example 7a, the two modifiers that modify the head noun are from the principal and to the students, while the three modifiers in Example $7 \mathrm{~b}$ are interesting, organised by the hall executives, and for the freshers. The modifiers in Example 7c are; important, in the college, performed by some prefects in the school and which are very helpful in ensuring that the school environment gets friendly.

Table 6 gives a summary of the number of NPs, with varying numbers of concatenated modifiers.

\begin{tabular}{lcclcccccc}
\hline & \multicolumn{3}{c}{ Level $\mathbf{2}$} & \multicolumn{3}{c}{ Level 3 } & \multicolumn{3}{c}{ Level 4+ } \\
\hline RESPOND. & FREQ & $\%$ & FREQ & $\%$ & & FREQ & $\%$ & Total & $\%$ \\
FEMALE & 793 & 45.3 & 577 & 76.7 & 131 & 91.6 & 1,501 & 56.7 \\
MALE & 958 & 54.7 & 175 & 23.3 & 12 & 8.4 & 1,145 & 43.3 \\
\hline TOTAL & 1,751 & & 752 & & & 143 & & 2,646 & 100.0
\end{tabular}

Table 6. Production of concatenated modifiers.

Table 6 offers a fairly contrasting picture to the one given in Table 5 . That is, whereas the male students often used the embedded modifiers, female students often used the concatenated modifiers. With reference to table 6 , it is seen that the female students dominate in the use of NPs with concatenated modifiers as compared to male students. Out of 2,646 NPs with concatenated modifiers, 1,501 which represent $56.7 \%$ was produced by the female students while 1,145 representing $43.3 \%$ was produced by the male students. The Chi-square computation confirmed that the difference in use of 
NPs with concatenated modifiers was significant. (Chi-square $=4.4916 \mathrm{E}-12, \mathrm{p}$ value $=$ 0.000). It can however be seen that in the case of NPs with two concatenated modifiers, the male students dominate in its use. The total number of NPs that had two concatenated modifiers is 1,751 . Out of that, 793 representing $45.3 \%$ were used by the female students, while 958 which represents $54.7 \%$ were also produced by the male students. In the use of NPs with three or more concatenated modifiers, the female students dominated in its use. Out of 752 NPs with three concatenated modifiers, 577 (76.7\%) were used by the female students, and 175 (23.3\%) were produced by the male students. In the case of NPs with four or more concatenated modifiers, the female students produced 131 representing 91.6\% while the male students also produced 12 (8.4\%). Thus, it can be established in this study that while male students liked to use concatenated phrases which have two modifiers, the female students used concatenated phrases with three or more modifiers. Such considerable variation between the male and the female students in the use of concatenated modifiers reinforces the different version of gender and language theory (Maltz \& Borker 1982; Tannen 1990, 1994). The above analysis establishes the fact that the female students used more concatenated modifiers than the male students while the male students used embedded modifiers more than the female students. This supports the existence of variation in the use of language by the two genders.

This work has established that female students used more complex NPs in their writing than the male students, thus supporting the assertion by Philips \& Reynolds (1987) that women have greater tendency toward informational redundancy and complexity in their speech than that of men.

\section{Discussion}

The key findings of the study showed that the male students used simple NPs more than the female students. A percentage of 46.0 of the total simple NPs was produced by the female students while $54.0 \%$ were produced by the male students. The prevalence of 
the male students' use of simple NP over the female students might be attributed to men being direct in their speech as Lakoff characterized men's language as “direct, clear and succinct" (Lakoff 1990: 205).

In the case of complex NP, the female students used it more in their writing than the male students. A percentage of 50.7 of the total NPs used by the female students was complex while $49.3 \%$ of the men's total NPs was complex. The difference is probably due to the fact that the female students' speech is more redundant and complex hence reflects in their English essay writings. Philips \& Reynolds (1987) claim that women's speech is more complex and have greater tendency toward informational redundancy and complexity in their speech than that of men's. This buttresses the claim by researchers (Maltz \& Borker 1982; Sheldon 1990; Tannen 1990, 1994) who follow the culture/difference approach of gender and language theory that men and women speak differently due to differences that are implemented during the socialization process. That is, boys and girls grow up being socialized so differently. Since men and women speak differently due to social difference, there is the probability for female students to use complex NPs while the males use simple NPs and vice versa.

Again, the findings revealed that the female students used more complex NPs but they had single modifiers. The male students on the other hand used fewer complex NPs but with multiple modifiers. Also, it was noted that the female students used NPs with concatenated modifiers more than the male students. The male students on the other hand used NPs with embedded modifiers more than the female students. That the female students used NPs with concatenated modifiers more than the male students and that the male students used embedded modifiers more than the female students confirm the existence of variation in the use of language by the two genders.

\section{Implications}

From the above discussions and findings from the Chi-square analysis, the following implications can be drawn from the study. First, it has implication on the scholarship on syntactic variation. The study has shown that syntactic variation can be conditioned by gender just as social class can also influence pronunciation. The study has, among other 
things, established that the female students of SDA College of Education use more complex NPs in their writing more than the male students. Also, the male students used more embedded modifiers than the female students while the female students also used more concatenated modifiers than the male students. This contradicts the views of some researchers that social factors are involved in syntactic variation (Cheshire 2005, Scherre \& Naro 1992). Teachers are those who train the trainees; thus, they equip the students with the necessary skills that they need to write their quiz essays. It is necessary for them, especially English tutors, to be more proactive in handling noun phrases to avoid redundancy. The study also has implication on language and gender theory. It has confirmed the Difference version of gender theory as compared to the Social construction version. This is because the differences in the findings, as confirmed by the Chi-square analysis, cannot be attributed to the social context because the students were in similar context when they wrote the quiz so the difference cannot be attributed to any other social factor than gender.

\section{Conclusion}

The study has looked at gender differences in the English essay quiz scripts of SDA College of Education students. Related literature to the study was reviewed. The research design, the sample and sampling technique of the target group, data collection procedure and data analysis plan were all discussed. Analysis and discussion of the data collected were also discussed. Attention was given to the syntactic variations in the construction of noun phrases conditioned by the gender of the writers. Frequency counts and Chi-square statistical procedures were used to analyse the data in the study. After analysing the data and discussing the analysis, conclusions were drawn from the analysis. The conclusion was that differences exist in the construction of NP between SDA College of Education female and male students. This means that gender influences the construction of NPs of the students' NP construction. This supports the Difference theory and debunks the Social construct. 


\section{Recommendations for future research}

Based on the findings and implications that stem from the study, there is the need for further investigation in any of the following suggested areas:

The first line of further research would be to examine the impact that the various courses that the students read have on their writing. A study in this direction will prove rewarding and consequently add to studies in language variation. This current study has focused on gender variation in the use of noun phrase evident in written language. Subsequent studies could look at gender variation in the use of noun phrase in spoken language. When such a suggested research is conducted, the unique features of each gender in natural use of language will be unearthed.

\section{References}

AmedAHE, F. K. (2002) Notes on Educational Research. Cape-Coast: University of Cape Coast (Unpublished).

AMOTT, T. \& J. MATTHAEIL (1991) Race, gender and work: A multicultural economic history of women in the United States, Boston: South End Press.

Baron, S. N. (2004) "See You on Line: Gender Issues in College Students Use of Instant Messaging", Journal of Language and Social Psychology, 23(4), 397-423.

BIBER, D. (1988) Variation across Speech and Writing, Cambridge: Cambridge University Press.

BIBER, D. (1997) Dimensions of register variation, New York: Cambridge University Press.

BiBER, D. \& E. Finegan (2009) “Adverbial stance types in English”, Discourse Processes, 11(1), 1-34.

Biber, D., S. Johnansson, G. LeeCH, S. Conrad \& E. Finegan (1999) Longman Grammar of Spoken and Written English, London: Longman.

BreND, R. M. (1975) "Male-female intonation patterns in American English", in B. Thorn \& Henly, Language and sex: Difference and dominance, Rowley, MA: Newbury House, 84-87.

BRIZENDINE, L. (2006) The Female Brain, Louisiana: Morgan Road Books.

BUTLER, J. $\left(1990^{2}\right)$ Gender trouble: Feminism and the subversion of identity, New York: Routledge.

CHAMBERS, R. (1992) Rural appraisal: rapid, relaxed and participatory, IDS Discourse Paper, 311, Brighton: Institute of Development Studies.

COATES, J. \& D. CAMERON (eds.) (1989) Women in their speech communities. New York: Routledge. 
CHESHIRE, J. (2005) "Syntactic variation and beyond: Gender and social class variation in the use of discourse-new markers", Journal of Sociolinguistics, 9, 479-508

COULMAS, F. (2006) Sociolinguistics, The study of speaker's choice, New Yok: Cambridge University Press

CRAWFORD, M. (1995) Talking difference: Gender and language, London: Sage Ltd.

CRYSTAL, D. (2004) The language revolution, Malden, MA: Polity Press.

DECAPUA, A. $\left(2017^{2}\right)$ Grammar for teachers: A guide to American English for native and non-native speakers, New York: Springer.

DRASS, K. A. (1986) "The effect of gender identity on conversation", Social Psychology Quarterly, 49(4), 294-301.

Frank, F. (1978) "Women's language in America: Myth and reality", in D. Butturff \& E. Epstein (eds.), Women's Language and Style, Akron, Ohio: L \& S Books, 47-61.

GOLAFSHANI, N. (2003) "Understanding Reliability and Validity in Qualitative Research", The Qualitative Report, 8, 597-607.

Grob, L. M., R. A. Meyers \& R. SCHUCH (1997) "Powerful/powerless language use in group interactions: Sex differences or similarities?", Communication Quarterly, 45, 282-304.

HAAS, A. (1979) "The acquisition of genderlect", Annals of the New York Academy of Sciences, 327, 101-113.

HERRING, S. C. (1994) "Politeness in computer culture: Why women thank and men flame", in M. Bucholt, A. C. Liang, L. A. Sutton \& C. Hines (eds.), Cultural performances: Proceedings of the third Berkeley Women and Language Conference, Berkeley Women and Language Group, 278-294.

HeRring, S. C. (2019) "Grammar and electronic communication", in C. Chapelle (ed.), The concise encyclopedia of applied linguistics. Hoboken, NJ: Wiley-Blackwell $<$ http://ella.ils.indiana.edu/ herring/CEAL.pdf>

KEY, M. R. (1975) Male/female language, Metuchen, NJ: Scarecrow.

Kramer, M. (1974) "Reality shock: Why nurses leave nursing", American Journal of Nursing, 75, doi10.1097/00000446-197505000-00041.

LABOV, W. (1972) Sociolinguistic patterns: Conduct and communication, 4, Philadelphia: University of Pennsylvania Press.

LAKOFF, R. (1975a) Language and woman's place, New York: Harper and Row.

LAKOFF, R. (1975b) "Linguistic theory and the real world", A Journal of Research in Language Studies, 25(2), 309-338. 
LAKOFF, R. (1990) Talking Power, San Francisco: Basic Books.

LINCOLN, Y. S. \& E. G. GUBA (1985) Naturalistic Inquiry. Beverly Hills, CA: Sage Publications.

MALTZ, D. \& R. BORKER (1982) "A Cultural Approach to Male-Female Miscommunication", in John Gumperz (ed.), Language and Social Identity, Cambridge: Cambridge University Press, 196216.

O'BARR, W. \& B. ATKINS (1980) "Women's language or powerless language?", in S. McConnellGinet, R. Borker \& N. Furman (eds.), Women and language in literature and society, New York: Praeger, 93-110.

PALMQUIST, M. (2013) The lexicon of the classroom: Language and learning in writing classrooms. Doctoral dissertation, Carnegie Mellon University.

PATTON, M. Q. (2001) Qualitative Evaluation and Research Methods, Newbury Park: Sage.

Peterson, C. (2000) "The future of optimism", American Psychologist, 55, 44-56. <https://dx.doi.org/10.1037/0003.066X.55.1.44 >

PHILIPS, S.U. \& A. REYNOLDS (1987) "The Interaction of Variable Syntax and Discourse Structure in Women's and Men's Speech", in S.U. Philips, S. Stelle \& C. Tabz (eds.), Language, Gender and Sex in Comparative Perspective, Cambridge: Cambridge University Press, 71-94.

QUiRK, R. S. GREenBaUm, G. LeECH \& J. SVARTVIK (1985) A comprehensive grammar of the English language, London: Longman.

RYDÉN, M. (1979) “On syntactic variability”, Nordic Linguistic Bulletin, 3(2), 4-15.

SARANTAKOS, S. $\left(1998^{2}\right)$ Social Research, New York: Palgrave.

SCherRe, M. M. P \& A. J. NARo (1992) "The Serial Effect on Internal and External Variables", Language Variation and Change, 4, 1-14.

SHELDON, A. (1990) "Pickle fights: Gendered talk in preschool disputes", Discourse Processes, 13, 531.

SHIELDS, S. A. \& E. C. DICICCO (2011) "The social psychology of sex and gender: From gender differences to doing gender", Psychology of Women Quarterly, 35(3), 491-499.

SOORI, A. \& A. A. ZAMANI (2012) "Language features in the writing of male and female students in English and Persian", European Journal of Social Sciences, 33(2), 324-329.

TANNeN, D. (1990) You Just Don't Understand: Women and Men in Conversation, New York: William Morrow.

TANNEN, D. (1994) Gender and Discourse, New York: Oxford University Press.

Thorne, B., C. Kramarae \& N. Henley (eds.) (1983). Language, gender and society, Rowley, Mass.: Newbury House. 
Dialectologia 26 (2021), 187-211.

ISSN: 2013-2247

TRUDGILL, P. (1974) The Social Difference of English Norwich, Cambridge: Cambridge University Press. 